\title{
Frequency-dependent sexual selection with respect to progeny survival is consistent with predictions from rock-paper-scissors dynamics in the European common lizard
}

\author{
Patrick S. Fitze ${ }^{1,2,3,4}$, Virginia Gonzalez-Jimena ${ }^{2,4}$, Luis M. San-Jose ${ }^{1,2,4}$, Benoit Heulin ${ }^{5}$ and \\ Barry Sinervo ${ }^{6,78}$
}

${ }^{1}$ Department of Ecology and Evolution, Université de Lausanne, Lausanne, Switzerland

${ }^{2}$ Department of Biodiversity and Restoration, Instituto Pirenaico de Ecología, Consejo Superior de Investigaciones Científicas, Jaca, Spain

${ }^{3}$ ARAID Foundation, Zaragoza, Spain

${ }^{4}$ Department of Biodiversity and Evolutionary Biology, Museo Nacional de Ciencias Naturales, Consejo Superior de Investigaciones Cientificas, Madrid, Spain

${ }^{5}$ Station Biologique, Centre National de la Recherche Scientifique, UMR 6553, Paimpont, France

${ }^{6}$ Department of Ecology and Evolutionary Biology, University of California, Santa Cruz, Santa Cruz, CA, USA

7 Départment d'Ecologie et Evolution, Université de Paul Sabatier, Toulouse, France

${ }^{8}$ Laboratoire Evolution et Diversiteì Biologique, Station d'Ecologie Expérimentale du Centre National de la Recherche Scientifique (Uniteì de Service et de Recherche 2936), Saint-Girons, France

\section{Edited by:}

Martin Stevens, University of

Exeter, UK

Reviewed by:

Molly E. Cummings, University of

Texas at Austin, USA

James Higham, New York

University, USA

${ }^{*}$ Correspondence:

Patrick S. Fitze, Department of

Ecology and Evolution, Université de

Lausanne, Biophore

1015 Lausanne, Switzerland

e-mail: patrick.fitze@unil.ch
Genetic polymorphism can be maintained over time by negative frequency-dependent (FD) selection induced by Rock-paper-scissors (RPS) social systems. RPS games produce cyclic dynamics, and have been suggested to exist in lizards, insects, isopods, plants, and bacteria. Sexual selection is predicted to accentuate the survival of the future progeny during negative FD survival selection. More specifically, females are predicted to select mates that produce progeny genotypes that exhibit highest survival during survival selection imposed by adult males. However, no empirical evidence demonstrates the existence of FD sexual selection with respect to fitness payoffs of genetic polymorphisms. Here we tested this prediction using the common lizard Zootoca vivipara, a species with three male color morphs (orange, white, yellow) that exhibit morph frequency cycles. In a first step we tested the congruence of the morph frequency change with the predicted change in three independent populations, differing in male color morph frequency and state of the FD morph cycle. Thereafter we ran standardized sexual selection assays in which we excluded alternative mechanisms that potentially induce negative FD selection, and we quantified inter-sexual behavior. The patterns of sexual selection and the observed behavior were in line with context-dependent female mate choice and male behavior played a minor role. Moreover, the strength of the sexual selection was within the magnitude of selection required to produce the observed 3-4-year and 6-8 year morph frequency cycles at low and high altitudes, respectively. In summary, the study provides the first experimental evidence that underpins the crucial assumption of the RPS games suggested to exist in lizards, insects, isopods, and plants; namely, that sexual selection produces negative-FD selection. This indicates that sexual selection, in our study exert by females, might be a crucial driver of the maintenance of genetic polymorphisms.

Keywords: sexual selection, behavior, female mate choice, intra-sexual selection, alternative male mating strategy, color polymorphism, rock-paper-scissors games, Zootoca vivipara

\section{INTRODUCTION}

Rock-paper-scissors (RPS) games can explain the maintenance of genetic polymorphisms over time and they give rise to evolutionary stable three-morph systems through negative-frequencydependent (FD) selection (Maynard Smith, 1982; Nowak, 2006; Sinervo and Calsbeek, 2006). RPS dynamics are characterized by fitness intransitivity whereby, each morph, when being at high frequency, is vulnerable to invasion by another morph. Fitness intransitivity produces morph frequency cycles. For example, in a true RPS game driven by male strategies (Sinervo and Calsbeek,
2006), one rare strategy has high fitness while the other rare strategy has low fitness relative to the common strategy. It has been suggested that such fitness intransitivity is the result of sexual selection and that it is the consequence of context-dependent female mate choice (Alonzo and Sinervo, 2001; Sinervo et al., 2007), but few evidence for this assumption exists. RPS games have been described in lizards (Sinervo and Lively, 1996; Sinervo et al., 2007), insects (Zhang et al., 2013), and bacteria (E. coli, Kerr et al., 2002), and it has been suggested by Sinervo and Calsbeek (2006), that they also exist in isopods (Shuster and 
Wade, 1991), other insects (damselflies, Svensson et al., 2005), and plants (Ågren and Ericson, 1996). In all these species (except in $E$. coli where direct competition may be the driving force; Kerr et al., 2002), sexual selection exerted by females might be at the origin of fitness intransitivity. For example, in the North American side-blotched lizards, Uta stansburiana it has been suggested that sexual selection with respect to male color morph (orange, blue, yellow) maximizes the son's fitness, i.e., the son's probability of success in future male-male contests. The predicted optimal mating strategy for females is: (a) when rock becomes common, to avoid mating rock and mate paper; (b) when paper becomes common, to avoid mating paper and mate scissors; and (c) when scissors becomes common, to avoid scissors and mate rock. This is because mating with common male morphs yields sons that, as adults, have low fitness due to negative FD competition among adult male morphs, i.e., during inter-generational competition (Alonzo and Sinervo, 2001; Sinervo et al., 2007). Similarly, in the European common lizard, Zootoca vivipara, sexual selection with respect to male color morph (orange, white, yellow) has been suggested to maximize fitness returns, by maximizing the progeny's survival during maturation, which depends on the frequency of adult males in a negative FD manner (Sinervo et al., 2007; San-Jose et al., 2014). In Drosophila melanogaster, the reproductive success of different genotypes of males depends on the competitor's genotype and thus on the frequency of the competing genotypes, potentially due to differences in sperm competitive ability among genotypes (Zhang et al., 2013). Thus, sexual selection may again explain the existence of fitness intransitivity, among genetic polymorphisms (Zhang et al., 2013). In the tristylous, self-incompatible herb Lythrum salicaria, three floral morphs (long-styled, mid-styled, short-styled) promote disassortative mating and they exhibit fitness intransitivity, the latter being governed by an interaction between negative FD selection among morphs and stochastic processes (Agren and Ericson, 1996; Sinervo and Calsbeek, 2006). This suggests that sexual selection on morphs (genetic polymorphisms) is a crucial driver of most of the described RPS games, but thin evidence exists for its existence and importance, and for the critical role of female preference, which might accentuate the outcome of male-male competition (Alonzo and Sinervo, 2001).

In the Pyrenean populations of the multiannual $Z$. vivipara rapid RPS-like color morph frequency cycles have been observed and a theoretical model suggests that a combination of density regulation (driving progeny survival) and sexual selection is required to generate these cycles (Sinervo et al., 2007). Male $Z$. vivipara exhibit distinct color morphs that exhibit phenotypes consistent with a single locus with 3 alleles (orange, $o$, yellow, $y$, and white, $w$; Sinervo et al., 2007). Color morph frequency of adult males is suggested to affect juvenile survival (Sinervo et al., 2007). More precisely, when $o$ males are common, $y$ juveniles have higher, and $w$ and $o$ juveniles have lower survival. When $y$ or $w$ adults are common the survival of $y$ juveniles is lower (Figure 5 and Table 1a in Sinervo et al., 2007). Therefore, survival payoffs of juveniles that encounter adult males, exhibit RPS intransitivity for the three critical juvenile and common adult morph combinations (Table 1a in Sinervo et al., 2007):

$$
\begin{gathered}
\omega_{y} \text { juvenile, common o adult }>\omega_{o \text { juvenile, common o adult }} \\
\omega_{w \text { juvenile, common } y \text { adult }}>\omega_{y \text { juvenile, common } y \text { adult }} \\
\omega_{o \text { juvenile, common } w \text { adult }} \geq \omega_{w} \text { juvenile, common } w \text { adult }
\end{gathered}
$$

(note that under transitivity $\omega_{o}$ juvenile, common $w$ adult would need to be smaller than $\omega_{w}$ juvenile, common $w$ adult $)$.

In contrast, if payoffs to females were only due to a density dependent RPS (as in Uta), females should avoid $y$ sires if $y$ is common, but be indifferent to rare $w$ and $o$ sire genotypes (see Table 1). However, a theoretical model showed that FD survival selection on juveniles cannot produce strong enough FD selection to produce the observed rapid morph frequency cycles and it suggests that FD sexual selection might provide the required additional FD selection (Sinervo et al., 2007). More precisely, the model assumes the existence of FD sexual selection on adult male morph with respect to the progeny's survival advantage conferred by the father's morph. When $o$ is common and $y$ invades $o$ (Figure 1; arrow A), the model predicts that females should avoid mating with $y$ males, because progeny will be exposed to a higher frequency of $y$ adults, where $y$ offspring die due to selflimitation (Sinervo et al., 2007). Females should indeed prefer $w$ over $o$ sires (despite the equally high survival of $w$ and $o$ sires; Table 1; Figure 1 arrow a), because $w$ alleles exhibit positive FD selection and confer a higher survival at maturity, leading to the production of many progeny during their tenure as reproductive adults (Sinervo et al., 2007). Moreover, when $o$ invades $w$ (Figure 1; arrow B), females should avoid $w$ (Figure 1; arrow) since progeny will be exposed to a higher frequency of $o$, where $o$ adults eliminate $w$ juveniles due to aggressive tactics and high resource holding potential (RHP). Females should indeed prefer $y$ (Figure 1; arrow b), since $y$ juveniles have a survival advantage given that they do not engage in RHP encounters, what makes them immune to RHP imposed by $o$. Moreover, $o$ offspring have a disadvantage due to self-limitation (Table 1). On the other hand, when $w$ invades $y$ (Figure 1; arrow C), progeny will be exposed to higher frequency of $w$, where $w$ and $o$ juveniles have high survival, and thus females should prefer $o$ over $w$ (Figure 1; arrow c) given their higher RHP (Sinervo et al., 2007). The existence of the two assumed cumulative mechanisms has recently been demonstrated (San-Jose et al., 2014), but although the model predictions regarding sexual selection are straightforward, to date no

Table 1 | Density dependent RPS payoffs for the recruitment of juvenile European common lizard morphs, $Z$. vivipara.

\begin{tabular}{lccc}
\hline \multicolumn{4}{c}{ Common adult color genotype } \\
\hline Juvenile survival & $\boldsymbol{o}$ & $\boldsymbol{w}$ & $\boldsymbol{y}$ \\
\hline 0 & $c<1$ & 1 & 1 \\
$w$ & 0 & 1 & 1 \\
$y$ & 1 & 0 & $k<1$ \\
\hline
\end{tabular}

Shown is juvenile fitness ( $\omega)$, when a given adult genotype is common (from Sinervo et al., 2007). Self-limitation of $o$ and y genotypes is represented by $c$ and $k$, respectively. 


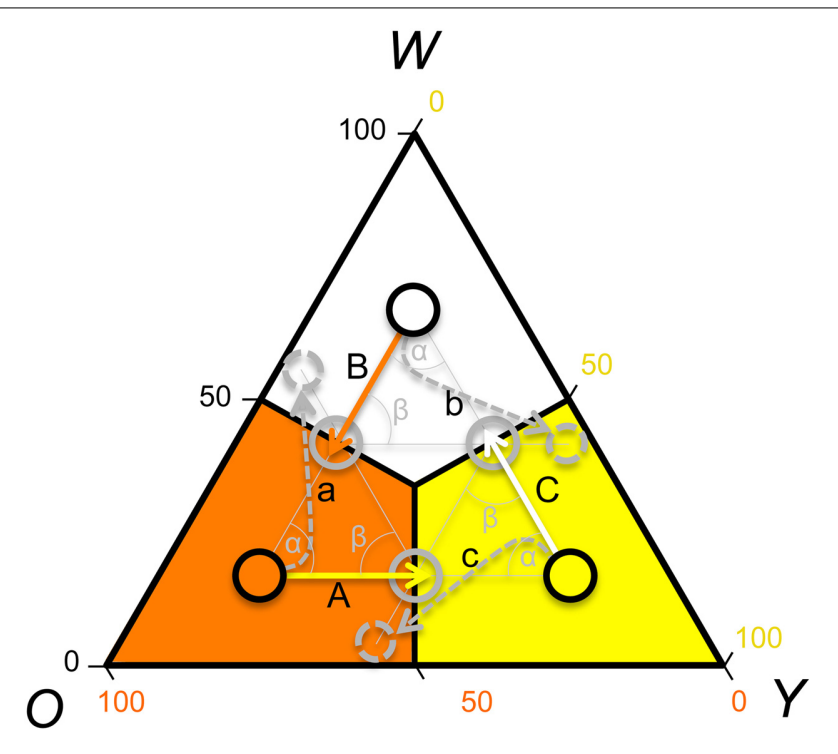

FIGURE 1 | Rock-Paper-Scissors dynamics: predictions of male color morph frequency cycling and sexual selection, according to a theoretical model (Sinervo et al., 2007). Shown is a ternary plot of the frequency of the putative male color alleles ( $w=$ white; $0=$ orange; $y=$ yellow). Population frequencies of the color alleles are delimitated with black circles. The predicted direction of the morph frequency change (Sinervo et al., 2007) is indicated with solid arrows and the arrow color indicates the future prevalent allele. The resulting predicted future color morph frequency is indicated with gray circles and the preferred color morph is indicated with a doted arrow and circle. Uppercase letters label the arrows of frequency change, and lowercase letters label arrows indicating preferred morphs during sexual selection. Theory predicts that if orange is the most prevalent color, the color morph circle should advance toward yellow (A). If white or yellow are prevalent, the color morph circle should advance toward orange (B), or white (C), respectively. Given that the maturing males (2-year cohort) achieve adulthood during summer, prevalence of adult orange males in spring will shift toward yellow predominance $(\mathbf{A})$ in late summer, leading to a circle advance toward yellow prevalence. Under yellow dominance yellow juveniles will survive worse and females should thus prefer mating with $o$ or $w$ males, and preferentially with $w$ males (a). In low altitude populations cycle periodicity is 3-4 years and thus the predicted frequency change and patterns of sexual selection can be explained with 3-4 frequency vectors [average angle of the frequency vectors $(\alpha)$ and of the frequency and sexual selection vectors $(\beta)=120-90^{\circ}$, while in high altitude populations with cycle periodicity of 6-8 years, 6-8 frequency vectors exist (average angle of frequency vectors and of the frequency and the sexual selection vectors $=60-45^{\circ}$ ). In any case, the predictions of the patterns of sexual selection depend on the exact location of the vectors, and in this graph we illustrate the predicted patterns of sexual selection with respect to three example vectors (average angle $\left.=120^{\circ}\right)$ for an idealized case where the attractor is $(1 / 3,1 / 3,1 / 3)$.

empirical evidence indicates that the suggested patterns of sexual selection may arise due to female mate choice. Thus, the existence of the mechanisms potentially explaining the observed frequency cycles is unclear, which compromises the claim that rapid RPS cycles can evolve in multiannual species with overlapping generations (Sinervo et al., 2007).

Here we experimentally investigate the existence of the basic model assumptions (Figure 1) using the common lizard $Z$. vivipara as a study species. First, we sampled three different study populations: Roncesvalles, Irau, and Somport and determined the color morph frequency of adult and maturing males to determine the location and change of the color morph frequency. Testing the congruence of the color morph cycle with the predictions from theoretical models is essential for confirming the model assumptions and for predicting expected local patterns of sexual selection. The determination of the color morph frequency and the direction of frequency change is crucial, given that populations significantly differ in the location of the attractor about which the RPS cycles orbit (Sinervo et al., 2007). In a second step, we ran three independent tests of mate preference and registered all copulations. In these tests only sexual selection could explain non-random mating and other mechanisms, potentially leading to FD selection, were excluded. We predicted that the frequency change and that the success of the male color morphs driven by female preference would be congruent with the predicted frequency changes indicated in Figure 1. Theoretical models assume that FD female mate choice leads to FD sexual selection (Sinervo et al., 2007) and an alternative explanation is FD usurpation success by male color morphs. To disentangle among these types of sexual selection, agonistic intersexual interactions were recorded in the Roncesvalles trials.

\section{MATERIALS AND METHODS \\ NATURAL HISTORY OF EUROPEAN COMMON LIZARDS IN THE PYRENEAN MOUNTAIN RANGE}

The European common lizard (Z. vivipara) of the Pyrenees is a small oviparous lizard (Heulin et al., 1991), consisting of four independent clades (Milá et al., 2013). In the oviparous Pyrenean populations, male common lizards exhibit distinct color morphs that behave like a single locus with 3 alleles (orange, $o$, yellow, $y$, and white, $w$; Sinervo et al., 2007), and that can be classified using two color scores (Sinervo et al., 2007), namely $o$ and $w$ score which account for the number of putative color alleles $(\mathrm{O}$ score: $0=w w, w y, y y, 1=y o, w o, 2=o o$; $\mathrm{W}$ score: $0=y y, o o$, yo, $1=w y$, wo, $2=w w$; Sinervo et al., 2007; note: differently colored individuals are extremely rare: San-Jose et al., 2008). Morphs differ optically, can be distinguished by spectrophotometry, and are determined by differential carotenoid deposition (San-Jose et al., 2012a, 2013). Carotenoid-ingestion significantly increases the carotenoid concentration in blood and liver (Fitze et al., 2009; San-Jose et al., 2013), but it does not affect the coloration, which is in line with genetic determination of the color morphs (Fitze et al., 2009; San-Jose et al., 2013). In contrast, iridophores exhibit condition-dependency and account for phenotypic plasticity (San-Jose et al., 2013; see also San-Jose and Fitze, 2013). The male's ventral coloration exhibits color morphs and is at the same time condition-dependent (Cote et al., 2008; Fitze et al., 2009; San-Jose et al., 2012b), i.e., phenotypically plastic. $O$ alleles positively and negatively affect endurance and survival, respectively (Sinervo et al., 2007). $Y$ alleles have a significant negative effect on body size (Sinervo et al., 2007), and $w$ alleles confer higher survival and higher endurance, the latter through allometry. Male color morph frequency cycles of cycles periodicity between 3 and 4 years in low and between 6 and 8 years in high elevation populations have been described (Sinervo et al., 2007). Oviparous females exhibit white bellies and no color morphs are present (Arribas, 2009). The ventral coloration of the oviparous Pyrenean 
clades differs from the viviparous clades inhabiting central and Northern Europe and Eurasia, where no color morphs have been described in males, but color morphs exist in females and exhibit significant heritable variation (Vercken et al., 2007, 2010; see also Cote et al., 2008).

Male and female common lizards have non-exclusive territories. Males emerge from hibernation between February and March, circa 1 month earlier than females, since their sperm is not fully functional after hibernation and spermiogenesis needs to be completed (Gavaud, 1991). Directly after female emergence, mating begins (Fitze et al., 2008; Bleu et al., 2011). Once a male spots a female, he approaches her, tries to grip her on the posterior abdomen with his mouth, and to twist his body around hers in order to copulate. The male's bite produces a scar on the female's belly and allows detection of copulations and copulation attempts. Females can avoid males by hiding, escaping, or by biting the approaching male (Fitze et al., 2010). Male persistence can result in violent mating struggles in which both males and females bite the potential mate partner and where it is not rare that both partners are rolling in a spiral across the landscape (Fitze et al., 2010). In mountainous areas three distinct age classes exist and lizards start to reproduce at the age of 2 years (in their 3rd spring), while in lowland populations two distinct age classes exist and reproduction can already start at the age of 1 year (in their 2nd spring: Boudjemadi et al., 1999; Sinervo et al., 2007; and exceptionally in their 1st spring: personal observations). The common lizard shows a complex mating system with intra- and intersexual selection (Fitze et al., 2008), context-dependent female mate choice (Fitze et al., 2010), and reproductive investment (Le Galliard et al., 2008), male sexual coercion (Fitze et al., 2005; Le Galliard et al., 2005), and best-of-bad-job strategies of males (Gonzalez-Jimena and Fitze, 2012). In male and female common lizards, sexual selection mainly acts on access to mate partners (copulation success) and despite intense experimentation, to date no evidence exists for post-copulatory sexual selection (Fitze and Le Galliard, 2008, 2011). Ventral coloration, body size, tail length, and bite force are the main predictors of male copulation success (Fitze and Le Galliard, 2008; Fitze et al., 2009; Huyghe et al., 2013).

\section{LIZARD ORIGIN AND POPULATION SAMPLING}

Lizards originated from 3 Pyrenean common lizard populations: Roncesvalles, Irau, and Somport. In Roncesvalles $\left(42^{\circ} 1^{\prime} \mathrm{N}, 1^{\circ} 19\right.$ E, $1062 \mathrm{~m}$ a.s.l.), the field site was regularly visited starting in March 2007, and the onset of the mating season was determined by the presence of mating scars resulting from copulation (Bauwens and Verheyen, 1985). On April 18th/19th males and unmated females, i.e., females without mating scars, were captured. In Irau $\left(43^{\circ} 2^{\prime} \mathrm{N}, 1^{\circ} 8^{\prime} \mathrm{W}, 950 \mathrm{~m}\right.$ a.s.l. $)$ visits started in April and captures lasted from April 22 to 24, 2008. Somport $\left(42^{\circ} 47^{\prime} \mathrm{N}, 0^{\circ} 31^{\prime} \mathrm{W}, 1640 \mathrm{~m}\right.$ a.s.l.) was visited starting in April and captures lasted from May 19th to 22th, 2009. In all three populations, lizards born the previous year were small, still black colored, and did not yet reproduce. During the capture sessions all captured lizards born $\geq 2$ summers ago were retained for color determination. Lizards born during the penultimate summer exhibited coloration and were smaller than adult lizards born $\geq 3$ summers ago. Age class was determined based on the conspicuous breakpoint in the size-frequency distribution (Sinervo et al., 2007).

\section{SCORING MALE COLOR MORPHS AND RECONSTRUCTION OF THE RPS FREQUENCY VECTOR FIELD}

The ventral scales are colored with one or two clearly distinct colors (see Sinervo et al., 2007, Figure 1 close-ups). Using a magnifying glass we optically determined putative homozygotes: orange $(o o)$, yellow $(y y)$, or white $(w w)$ morph, and putative heterozygotes: yo, wo, wy (Sinervo et al., 2007). Male morph was scored as 0,1 , or $2 o$, and 0,1 , or $2 w$ putative color alleles (Alonzo and Sinervo, 2001; Sinervo et al., 2001, 2007; Sinervo and Clobert, 2003), and referred to as $\mathrm{O}$ and W score (for further details, see Statistical models of mate choice and Sinervo et al., 2007; San-Jose et al., 2013). Modeling color scores as covariates allows for tests of putative additive genetic effects, interaction terms, and putative genetic dominance (quadratic terms; Sinervo et al., 2007).

Low elevation populations (300 $\mathrm{m}$ a.s.l.) show 3-4 year male color morph frequency cycles while high elevation sites (1500$1700 \mathrm{~m}$ a.s.l.) show 6-8 year cycles (Sinervo et al., 2007). Cycle length is a function of male growth, which is tightly linked to local climatic conditions and thus to temporal and spatial variation (e.g., Marquis et al., 2008). Our lowest elevation population (Irau) was located at $950 \mathrm{~m}$ a.s.l. and exhibited 3 distinct age cohorts, indicating that RPS cycles of all populations last more than 4 years in all studied populations. In spring, lizards born the previous year were small $(\leq 48 \mathrm{~mm}$, or $\leq 45 \mathrm{~mm}$ ), and did not yet reproduce, those born 2 years ago were of small body size, at which reproduction is rare (Fitze et al., 2010), and those born $\geq 3$ years ago were mature adults. Lizards born 2 years ago undergo maturation during spring/summer and become adults in autumn, i.e., when juveniles are exposed to FD survival selection. As in the Ossau valley where color morph frequency cycles have first been described (Sinervo et al., 2007), changes in putative allele frequency were determined by binning 2 distinct age cohorts based on the size discontinuity (Roncesvalles and Irau: snout-vent length (SVL) of lizards $\geq 3$ years ago born $>53 \mathrm{~mm}$; 2 years ago born, $48 \mathrm{~mm}<\mathrm{SVL} \leq 53 \mathrm{~mm}$; Somport, which is at the highest altitude with shortest lizard activity: SVL of lizards $\geq 3$ years ago born $>52 \mathrm{~mm}$, and 2 years ago born, $45 \mathrm{~mm}<\mathrm{SVL} \leq$ $52 \mathrm{~mm}$ ). For each cohort the frequency of the color scores was determined. The frequency of the adult cohort corresponds to the frequency of the males involved in sexual selection in spring, when the maturing cohort (born the penultimate summer) is not yet mature. Maturing males ( $<2$ years old) become mature at the age of 2 years (in summer), when progeny (produced in spring) will be born and exposed to RPS density regulation. Thus, the combined frequency (adult + maturing males) corresponds to the frequency of the adults present in autumn, when maturing lizards are exposed to FD survival selection (see also Figure 2). Comparison between adult and adult + mature male frequency thus allows the measurement of color morph frequency change across generations, which is essential for predicting expected local patterns of sexual selection, given that populations appear to differ significantly in the location of the attractor about which the RPS cycles orbit (Sinervo et al., 2007). Significance of changes 


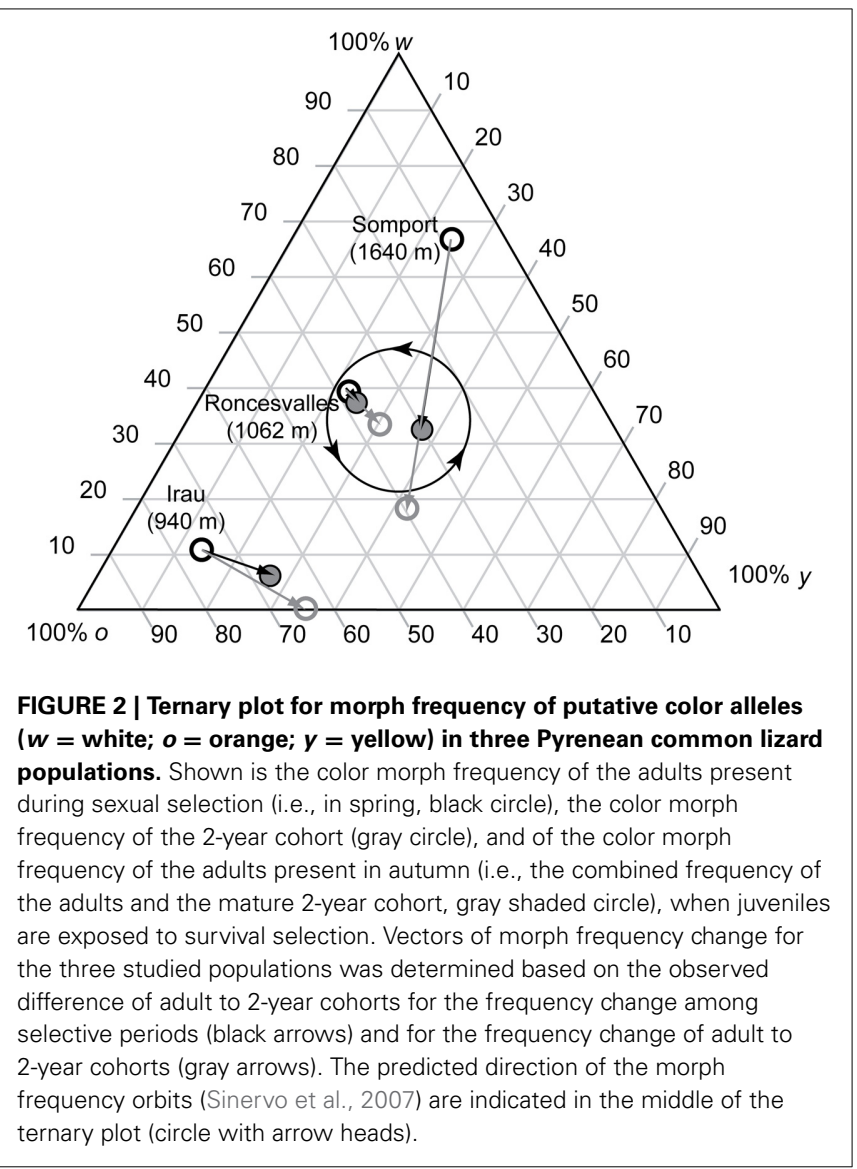

in color morph frequency across generations was assessed using Chi-square tests.

\section{TRIADIC SEXUAL SELECTION TRIALS}

Triadic sexual selection trials were conducted under standardized conditions to exclude mechanisms different from sexual selection that may also generate FD cycles.

Captured lizards brought to the Instituto Pirenaico de Ecología in Jaca (Huesca), where they were housed in individual terraria (size: $25 \times 15 \times 15 \mathrm{~cm}$ ) under standardized conditions (heat, light, water, and food) to make sure that mating patterns could not be influenced by color morph frequency during transport or housing. Every 4 days, lizards were fed with wax moth larvae (Galleria mellonella) and provided with water ad libitum (Fitze et al., 2008).

Following capture, lizards could acclimate to the lab conditions for 2 days. Three males of similar, age (same age cohort), body size (SVL; $\pm 2 \mathrm{~mm}$ ), and body condition $( \pm 0.3)$ were randomly assigned to triads and individually marked with a small white dot. Males of a triad thus differed in coloration, but not in other traits relevant to sexual selection (Fitze and Le Galliard, 2008; Fitze et al., 2008). Thereafter, a randomly chosen female (Roncesvalles: $N=22$; Somport: $N=12$; Irau: $N=$ 14) was introduced in one corner of an escape-proof wooden box $\left(2500 \mathrm{~cm}^{2}\right)$, illuminated with a $40-\mathrm{W}$ bulb that provided light and heat. Two to four min later a randomly chosen triad was placed in the opposite corner of the box and copulations were recorded over a 3-h period. Mating trials started at 09:00 $\mathrm{h}$ and the last trial started no later than 16:00 h. If copulations were not yet finished after $3 \mathrm{~h}$, lizards were removed from the mating arena $5 \mathrm{~min}$ after the end of the copulation, and placed back in their individual terraria.

To determine whether copulation could be the result of female choice, behavior was recorded with a video camera during the Roncesvalles trials and intersexual interactions quantified. For each lizard pair the actor and receiver were determined based on the following aggressive behaviors: fleeing, chasing, biting, fighting, and tail flicking (Gonzalez-Jimena and Fitze, 2012). An actor that makes a receiver flee and tail flick, and that chases, bites and attacks it, is dominant. In an intersexual selection context, these behaviors indicate, in females, rejection of the male and, in males, interest and usurpation attempts. Behavioral counts before vs. after copulation (Fitze et al., 2008) were taken into account, and behaviors during copulation were not included. Principal components (PCs) of behaviors expressed before and after copulation were computed to avoid multiple testing (Tables 2, 3). All lizards were used for one single trial, and thereafter released where captured.

\section{STATISTICAL MODELS OF MATE CHOICE}

Copulation probability was modeled using generalized linear mixed models (GLM) with binomially distributed errors and a logit link (Crawley, 2007). O and W color scores, and their interactions, were covariates, and triad was modeled as a random factor. In the presence of overdispersion a quasibinomial error distribution was used.

To test how aggressive behavior affected copulation probability, behavioral variables were summarized using PC analyses. More specifically, all principle component explaining $>10 \%$ of the variance were extracted for each sex (Tables 2, 3), and used as covariates in the GLMs on copulation probability. In both sexes, only PC1 had significant effects and thus, the other PCs were dropped from the models. GLMs were modeled with linear terms $\left(\mathrm{O}, \mathrm{W}, \mathrm{PC}_{\text {female }}, \mathrm{PC} 1_{\text {male }}\right)$, an interaction term for the color scores $(\mathrm{O} \times \mathrm{W})$, interaction terms for aggressive female $(\mathrm{O} \times$ $\left.\mathrm{PCl}_{\text {female }}, \mathrm{W} \times \mathrm{PC1}_{\text {female }}\right)$, and male behavior $\left(\mathrm{O} \times \mathrm{PC1}_{\text {male }}\right.$, $\left.\mathrm{W} \times \mathrm{PCl}_{\text {male }}\right)$ with color scores, the interaction between aggressive male and female behavior $\left(\mathrm{PC1}_{\text {female }} \times \mathrm{PC} 1_{\text {male }}\right)$, as well as quadratic terms $(\mathrm{O} \times \mathrm{O}, \mathrm{W} \times \mathrm{W})$ and triad as random effect (not significant in all models).

$\mathrm{O}$ and $\mathrm{W}$ color scores compare additive effects of $o$ and $w$ alleles relative to $y y$, which is zero on both $\mathrm{O}$ and $\mathrm{W}$ scores. The interaction term $\mathrm{O} \times \mathrm{W}$ assesses differences in genetic dominance interactions (e.g., among wo vs. yo vs. wy) on the expression of a given trait (Sinervo et al., 2007), i.e., over- or under-dominance, and quadratic terms test for significant curvature along a given color axis.

\section{RESULTS}

\section{COLOR FREQUENCIES AND COLOR CYCLE}

Color frequency changed significantly from high $w$ and $o$ toward $y$ color in Roncesvalles [Figure 2, $\chi_{(2)}^{2}=47.76, P<0.01, N=66$ males] and from high $o$ and very low $w$ and $y$ toward $y$ color in Irau [Figure 2, $\chi_{(2)}^{2}=40.63, P<0.01, N=25$ ]. In Somport the 
Table 2 | Explained variance and Eigenvectors for principal components (PCs) derived from Principle Components Analysis (PCA) of female aggression directed toward males after copulation.

\begin{tabular}{|c|c|c|c|c|c|}
\hline Principal component & PC1 & PC2 & PC3 & PC4 & PC5 \\
\hline Variance explained (\%) & 28.107 & 26.016 & 20.602 & 13.098 & 12.177 \\
\hline \multicolumn{6}{|l|}{ EIGENVECTORS } \\
\hline$N$ bites delivered to male & 0.533 & 0.454 & -0.022 & -0.692 & -0.175 \\
\hline$N$ times chasing male & 0.227 & -0.056 & 0.909 & 0.022 & 0.345 \\
\hline$N$ times making male flee & 0.414 & -0.533 & -0.366 & -0.175 & 0.616 \\
\hline$N$ times making male move tail & 0.581 & -0.409 & 0.056 & 0.334 & -0.617 \\
\hline
\end{tabular}

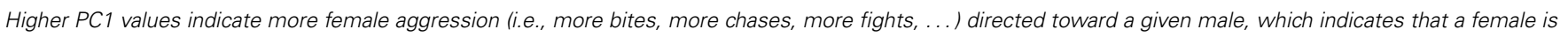
not willing to re-mate with this male.

Table 3 | Explained variance and Eigenvectors for PCs derived from PCA of male aggression directed toward females before copulation.

\begin{tabular}{|c|c|c|c|c|c|}
\hline Principal component & PC1 & PC2 & PC3 & PC4 & PC5 \\
\hline Eigenvalue & 2.536 & 1.051 & 0.676 & 0.386 & 0.351 \\
\hline Variance explained (\%) & 50.723 & 21.019 & 13.521 & 7.721 & 7.017 \\
\hline \multicolumn{6}{|l|}{ EIGENVECTORS } \\
\hline$N$ bites delivered to female & 0.516 & -0.099 & -0.406 & 0.453 & -0.595 \\
\hline$N$ times making female flee & 0.424 & -0.113 & 0.868 & 0.231 & -0.028 \\
\hline$N$ times making female move tail & 0.475 & -0.432 & -0.279 & -0.051 & 0.712 \\
\hline
\end{tabular}

Higher PC1 values indicate more male aggression (i.e., more bites, more chases, more fights, ...) directed toward the female and thus more interest in copulating.

color frequency changed from high $w$ and very low $o$ toward high $o$ color [Figure 2, $\chi_{(2)}^{2}=100.62, P<0.01, N=60$ ].

\section{COPULATION SUCCESS OF MALE COLOR MORPHS}

There existed a significant interaction between $\mathrm{W}$ and $\mathrm{O}$ color scores $\left[t_{(1,34)}=-2.27, P=0.030\right]$ in Roncesvalles. The $y y$ males copulated with the lowest probability $(0.33 \pm 0.33 S E)$, and $w w$ $(0.75 \pm 0.25 S E), o o(0.88 \pm 0.13 S E)$ and yo males $(0.75 \pm 0.16$ $S E)$ copulated with the highest probabilities. In Irau, W score $\left[t_{(1)}=13.45, P=0.024\right]$, and $O$ score $\left[t_{(1)}=8.33, P=0.038\right]$ positively affected the copulation probability and the copulation probability of $w$ males was highest $(0.73 \pm 0.14 S E)$, followed by oo males $(0.47 \pm 0.13 S E)$. Y was avoided $(0.08 \pm 0.08 S E)$. W males were 2.64 times more likely to copulate than males without $w$ alleles. In Somport, a high elevation population, yo males had the highest copulation probability $(0.80 \pm 0.20 \mathrm{SE})$, followed by $y y$ males $(0.50 \pm 0.29 S E)$, and $w w$ and $w o$ males had the lowest copulation probability $(0.13 \pm 0.13 S E ; 0 \pm 0 S E)$. $\mathrm{W}$ color score negatively affected copulation probability $\left[z_{(1)}=\right.$ $2.04, P=0.041]$. Copulation probability of males without $w$ alleles $(0.58 \pm 0.15 S E)$ was 1.9 and 4.5 times higher than that of males with one $(0.31 \pm 0.12 S E)$, or two $w$ alleles $(0.13 \pm$ $0.13 S E$ ), respectively. Thus, $y$ and $o$ males had a copulation advantage.

\section{INFLUENCE OF FEMALE AND MALE AGGRESSION AND MALE COLOR DURING RONCESVALLES MATING TRIALS}

Females exhibited very little aggressive behavior before copulation, but they exhibited considerable variation in aggressive behavior to males after copulation. Therefore, only female aggressive behavior after copulation could be analyzed. The first PC $\left(\mathrm{PCl}_{\text {female }}\right)$ explained $28 \%$ of the variance in female aggression (Table 2) and all aggressive female behaviors conducted toward males loaded positively (Table 2 ). Female aggression specifically directed toward a given male, is indicative of female unwillingness to re-mate, especially after copulation thus enhancing the fertilization of the eggs by a single sire (i.e., after copulation). Female aggression was significantly correlated with male copulation success $(\mathrm{PC} 1 \times \mathrm{O}$ interaction), and the effect of $\mathrm{O} \times \mathrm{W}$, which drives female preference for $o$ and $w$ over $y$, remained highly significant (Table 4).

The first PC explained $51 \%$ of the variance in male aggression ( $\mathrm{PC} 1_{\text {male }}$, Table 3 ) conducted before copulation, and all aggressive male behaviors loaded positively (Table 3 ). There was no significant interaction with color score (Table 4, all interactions between color score and $\mathrm{PC}_{\text {male }}$ were not significant), indicating that male aggressive behavior did not affect copulation success (note that PC2 was not significant in males and females). 
To isolate the form of female aggression toward male color morphs, tests for each of the three color scores (Y, O, W) were carried out. In Y models, male copulation success was affected by a significant interaction between female aggression and $y$ score $\left[\mathrm{PCl}_{\text {female }} \times \mathrm{Y}: \chi_{(1)}^{2}=4.52, P=0.02\right.$, Figure 3A $]$. In males with $\mathrm{Y}$ score 1 or 2 , copulating males were more often aggressed by females than unsuccessful males, while in males with $\mathrm{Y}$ score 0 the contrary was the case: males with higher copulation probability were aggressed less often than those that did not copulate. Overall, $y$ males, which did manage to copulate, were more often aggressed by females than unsuccessful $y$ males and non- $y$ males (Figure 3A). In $o$ models, there was also a significant interaction between female aggression and color score $\left[\mathrm{PCl}_{\text {female }} \times\right.$ O: $\chi_{(1)}^{2}=4.54, P<0.01$ ], showing that $o$ males that were successful at copulation received very little aggression (Figure 3B, front oo corner) and may thus have been preferred, while successful non-orange males were more often aggressed by females (Figure 3B, corner in the back of the figure). In contrast, in W

Table 4 | Probability of copulation in relation to color score and male and female aggression (PC1).

\begin{tabular}{lccc}
\hline Parameter & $\chi^{\mathbf{2}}$ & $\boldsymbol{P}$ & Estimate \pm SE \\
\hline $\mathrm{W}$ & 3.092 & 0.079 & $2.22 \pm 1.27$ \\
$\mathrm{O}$ & 0.100 & 0.752 & $0.42 \pm 1.32$ \\
$\mathrm{O} \times \mathrm{W}$ & 7.975 & 0.005 & $5.25 \pm 1.86$ \\
$\mathrm{PC} 1_{\text {female }}$ & 0.509 & 0.476 & \\
$\mathrm{PC} 1_{\text {female }} \times \mathrm{O}$ & 4.555 & 0.033 & $4.16 \pm 1.94$ \\
$\mathrm{PC} 1_{\text {female }} \times \mathrm{W}$ & 0.015 & 0.902 & \\
$\mathrm{PC} 1_{\text {male }}$ & 2.857 & 0.091 & $-0.91 \pm 0.54$ \\
$\mathrm{PC} 1_{\text {male }} \times \mathrm{O}$ & 0.104 & 0.748 & \\
$\mathrm{PC} 1_{\text {male }} \times \mathrm{W}$ & 2.598 & 0.107 & $2.03 \pm 1.26$ \\
\hline
\end{tabular}

Triad modeled as a random effect (included in the model but not shown here) was not significant. models the interaction between female aggression and $\mathrm{W}$ score was not significant $\left[\mathrm{PC}_{\text {female }} \times \mathrm{W}: \chi_{(1)}^{2}=1.67, P=0.16\right]$, and the female aggression surface was relatively flat, indicating little female aggression toward $w$ males.

Male aggressiveness was reported to differ among color morphs (Sinervo et al., in review) and may override female choice (Fitze and Le Galliard, 2008, 2011). In this study, total male bites, one of the most aggressive behaviors exhibited by males, plotted as a function of $\mathrm{O}$ and $\mathrm{Y}$ scores (Figure 4) exhibited significant (Table 5), and linear effects of $o$ and $y$ score on male aggression (Table 5), and thus a simple plane sloping upwards to yo, with both $o o$ and wo males exhibiting more aggression than $w w$ and $y y$ males.

\section{DISCUSSION}

RPS dynamics can explain how genetic polymorphisms are maintained over time (Maynard Smith, 1982; Nowak, 2006; Sinervo and Calsbeek, 2006). Taxa where RPS dynamics have been suggested to be at work include reptiles, insects, isopods, bacteria, and plants and in most of them sexual selection might drive the observed dynamics. Theoretical models further suggest that sexual selection is imposed by female mate choice, which accentuates the outcome of male-male and trans-generational competition (Alonzo and Sinervo, 2001; Sinervo et al., 2007), and experimental evidence underpins this assumption (San-Jose et al., 2014). Here we experimentally tested in three independent common lizard populations, whether sexual selection is in line with the observed RPS dynamics and female mate choice, by measuring the color morph frequency change and the patterns of sexual selection, the latter in the absence of alternative mechanisms that can produce non-random mating patterns.

In all three populations the observed color morph frequency change was anti-clock wise (Figure 2). The direction of the change was consistent with the predictions of the RPS models (Figure 1) and the frequency cycle directions observed in three unrelated populations (Sinervo et al., 2007). Color morph
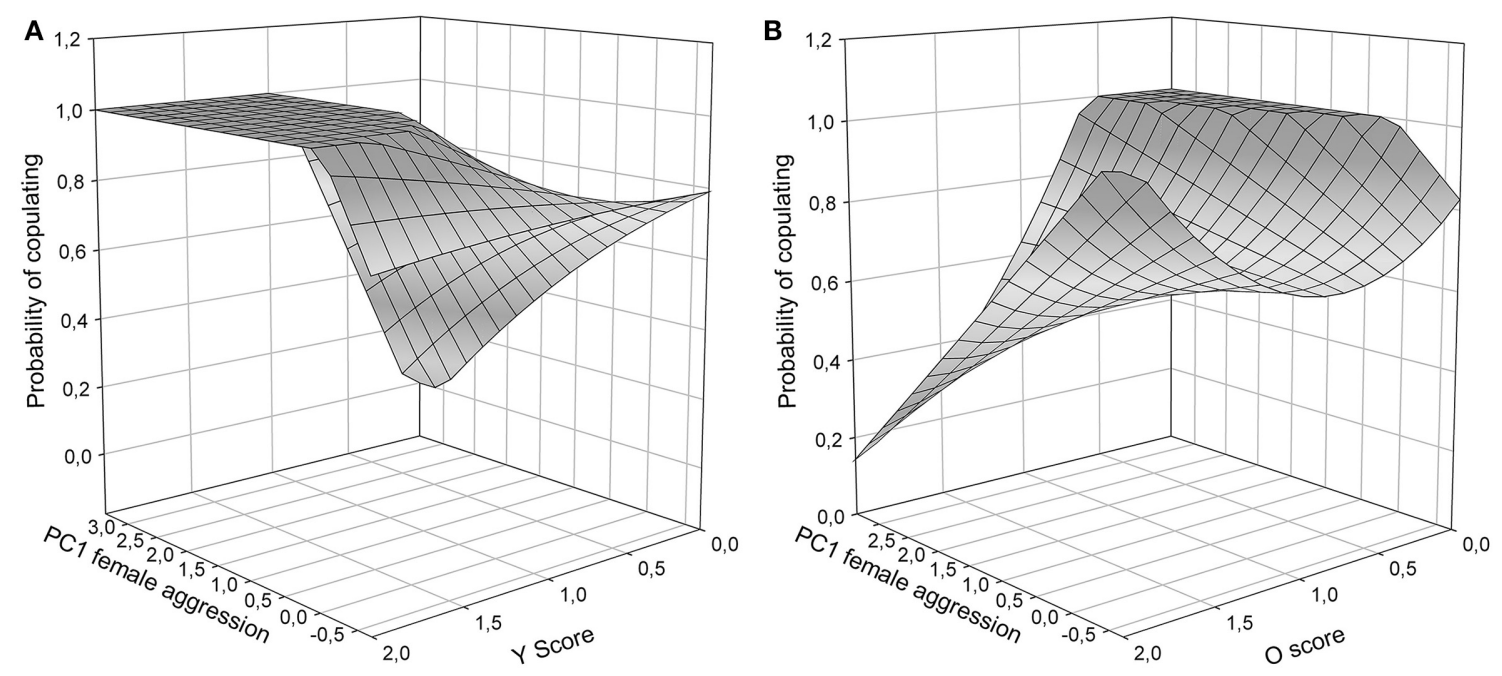

FIGURE 3 | Copulation success during Roncesvalles trials as a function of female aggressive behavior (1st PC axis) and male color scores: (A) Y score, and (B) $\mathbf{O}$ score. $O$ and $Y$ surfaces were significant (see results), and no statistically significant support for the W surface existed (surface not shown). 


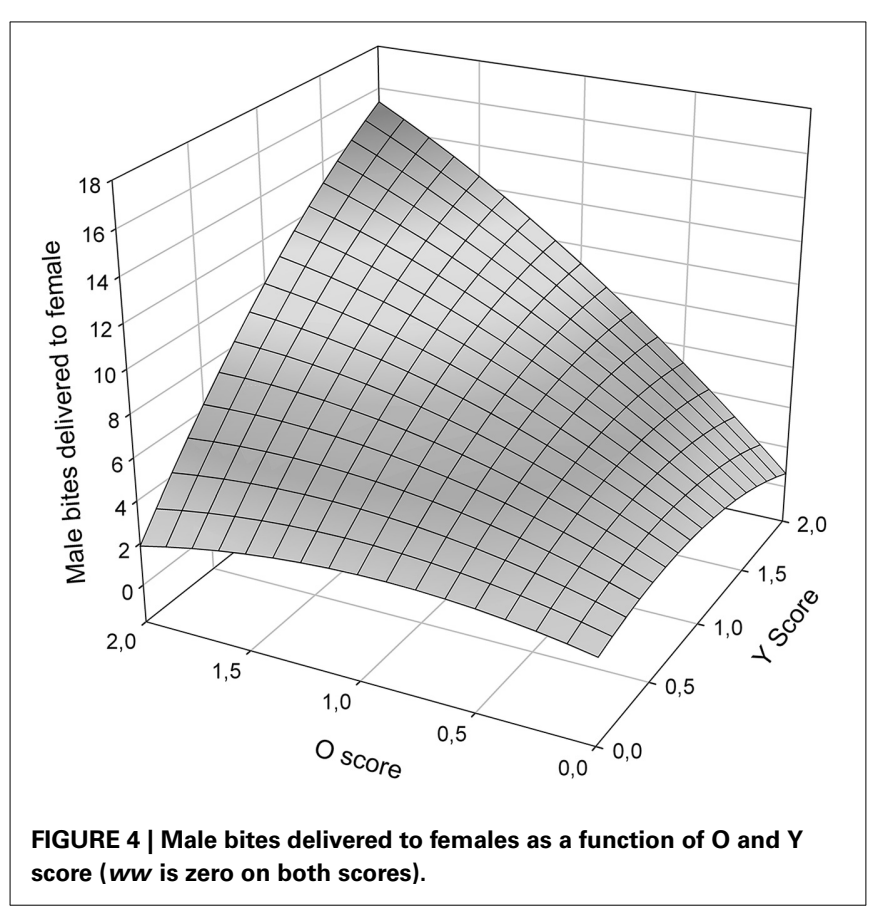

Table 5 | Total number of bites delivered to females before and after copulation as a function of the male's $o$ and $y$ score.

\begin{tabular}{lccr}
\hline Parameter & $\boldsymbol{F}_{(\mathbf{1}, \mathbf{5 0 )}}$ & $\boldsymbol{P}$ & Estimate $\pm \boldsymbol{S E}$ \\
\hline $\mathrm{O}$ & 5.094 & 0.028 & $2.421 \pm 1.07$ \\
$\mathrm{Y}$ & 5.791 & 0.020 & $3.22 \pm 1.34$ \\
$\mathrm{O} \times \mathrm{Y}$ & 4.829 & 0.182 & \\
$\mathrm{Y}^{2}$ & 0.565 & 0.456 & \\
$\mathrm{O}^{2}$ & 0.522 & 0.473 & \\
\hline
\end{tabular}

Bites delivered during the act of copulation, when the male bites the female's lower belly in a copulatory hold, were not considered since the copulating male bites the female during the entire copulation. Triad modeled as a random effect was not significant and thus not shown here.

frequencies in the Roncesvalles and Irau populations were moving from orange toward yellow prevalence and in the Irau population white alleles were almost lacking (Figure 2). In this context sexual selection should penalize $y$ males, given that progeny will mature when adult $y$ males will be prevalent, which imposes reduced survival of $y$ progeny during maturation (see Table 1 and predictions in introduction). In other words, $w$ and $o$ males should have higher success than $y$ males (Table 1). In contrast, in Somport, a high elevation population, the color frequency changed from high $w$ to $o$ (Figure 2). According to the predictions (Figure 1), $w$ males should have low and $y$ males high mating success (Figure 1), because maturing progeny will be exposed to genic selection (Sinervo et al., 2007) when $o$ male morphs will be common and $w$ progeny will recruit poorly (Table 1).

In our experiment, mechanisms different from sexual selection were excluded and in Roncesvalles and Irau $y$ males had the lowest copulation success, which is in line with the predictions (Figure 1). In Irau, where $w$ alleles were almost absent, the copulation success of $w$ males compared to $o$ males was 1.71 times higher and morphs with $w$ alleles were 2.64 times more likely to copulate than all other morphs, while in Roncesvalles the copulation success of $o$ compared to $w$ males and of $w$ compared to $y$ males was 1.28 and 1.52 times higher. This difference arises due to a difference in the location of the morph frequency change vector, which is an essential determinant of the RPS cycle orbit (Sinervo et al., 2007). In Irau $y$ started to invade $o$ and $w$ was almost completely absent (Figure 2, lower left corner of the ternary plot). In this situation $w$ provides an additional advantage because $w$ alleles exhibit positive FD selection and high adult survival. In contrast, the Roncesvalles population was close to equilibrium of the three color alleles (i.e., close to the center of the ternary plot) and thus already a slight mating bias moves the cycle toward prevalence of a given allele (note: In Irau, a small change would not change dramatically allele prevalence). Thus, a shift of a few $w$ males will move the frequency from yellow to white prevalence, and as a consequence $o$ males would have advantage over $w$ males. In the Somport population $y y$ and yo males showed the highest copulation success, while mating success of $w w$ and $w o$ males was lowest, which is in line with the predictions [note that in high elevation populations the average yearly morph frequency change $(\alpha)$ is $45-60^{\circ}$ ].

RPS theory also predicts that female mate choice rather than male-male competition explains color morph cycling in Z. vivipara (Sinervo et al., 2007). Our findings are in line with these predictions and with context-dependent female mate choice (Fitze et al., 2010) based on male color morph frequency (Alonzo and Sinervo, 2001) for several reasons. First, morph specific copulation success differed among Irau/Roncesvalles and Somport experiments and was in line with population specific predictions from color morph cycling. These results cannot be explained by male strategies given that male color morphs were homogeneously distributed among triads and male strategies should have thus generated the same outcome in all three populations. Second, in the behavioral analyses male aggression toward females did not significantly affect copulation success (Table 4), while female aggression and color morph were significant. This suggests that male usurpation may have played a minor role. Third, in Roncesvalles $w w$ and oo morphs were most successful and copulating $w w$ and oo morphs (Figure 3B, front oo corner) received less female aggression than copulating yy males (Figure 3A, left plateau). This indicates that females avoid copulating with $y y$ males and the pattern cannot be explained by unspecific postcopulatory aggression of females toward males (under which no significant relationship with male morph would be predicted), nor by aggression directed toward males that did not yet mate, e.g., due to increased interest for novel males. Fourth, $y$ males were less successful and those that had high copulation success received a lot of female aggression (Figure 3A, left plateau). These lines of evidence suggest that male copulation success was mainly driven by female preference, what may explain why male aggression did not affect male copulation success (Table 4). However, yo males delivered more bites to females than any other male morph (Figure 4), and the high female aggression $(\geq 1.5)$ against successful yo males (Figure 3A) suggest that females did not prefer yo males. In addition yo males may have been able to increase 
copulation success through aggression and usurpation. This suggests that female mate choice may predominantly cause the observed patterns of sexual selection, with a minor component potentially arising from some aggression and usurpation.

Our results also indicate that male color morph frequency previous to, or right after hibernation, determined the observed pattern of sexual selection, because color morph frequency experienced during the mating trials (i.e., color morph frequency of the male triad) could not explain the observed mating patterns. In the mating experiments females were presented to three adult and no maturing males, indicating that during maturation progeny would be exposed to the adult morph frequency of the triad (note: absence of maturing males reflects a year with low reproductive success or low juvenile survival). Predicted optimal mating patterns (Table 1) with respect to the triad color morph frequency were $w$ avoidance and $y$ preference at Irau (in 100\% of the triads), and $y$ avoidance and wo preference at Somport (in $90 \%$ of the triads), which clearly contrast with the observed patterns ( $w$ preference and $y$ avoidance at Irau; and $w$ avoidance at Somport).

The level of female mating discrimination, $m$, is a critical parameter required to generate rapid color morph frequency cycles (Sinervo et al., 2007). Strong context-dependent mate preference leads to color morph frequency cycles of 3-4 years at low and 6-8 years at high altitude, while weak preference leads to morph frequency cycle periodicity of $>16$ generations (see Alonzo and Sinervo, 2001; Figure 7 in Sinervo et al., 2007). The mating discrimination, $m$, of Roncesvalles females for $w$ and $o$ compared to $y$ (when yellow is becoming common) was on average 1.4 times higher than random expectations ( $m$ corresponds to the average mating probability of $w$ or o alleles per average mating probability of the $y$ alleles). In Irau $m$ was 7 times higher and the discrimination behavior of Somport females for $y$ was 2.1 times higher than for $o$ and $w$. Thus, $m$ is high enough $(m>$ 1.3, Figure 7B in Sinervo et al., 2007) to generate rapid 3-4 and 6-8 year generation cycles observed in nature. Moreover, the difference in mate discrimination between Roncesvalles and Irau is in line with the predictions derived from the location of the frequency change vector in the ternary plot, i.e., a frequency vector being closer to $w$ prevalence should lead to lower $w$ discrimination (see as well previous discussion). The other critical parameter necessary for rapid RPS cycles is targeted discrimination, $d$, by adult male genotypes on maturing juveniles. In this study, we cannot estimate $d$. However, with a value of $m \geq 1.4$, the discrimination behavior by males against juvenile genotypes needs only be $d=1.1$ times greater than random expectations (i.e., $d=1$ ). Thus, the fit between the morph frequency cycle, sexual selection and the magnitude $m$ observed in all three populations, match predictions derived from the RPS model and context-dependent female mate choice (Alonzo and Sinervo, 2001, 2007).

In conclusion, our study shows that the morph frequency cycle and the patterns of sexual selection measured under standardized conditions and in three independent populations are congruent with the predictions derived from theoretical models (Figure 1, Sinervo et al., 2007). This demonstrates that the basic assumption (i.e., FD selection accentuated by sexual selection with respect to future fitness benefits during inter-generational genic selection) is fulfilled. This finding strengthens the models explaining the maintenance of genetic polymorphisms by rapid cyclic RPS or RPS-like dynamics (Sinervo et al., 2007). The study thus provides the first rigid direct observational evidence that behavior (i.e., sexual selection) might be responsible for the maintenance of genetic polymorphisms. RPS or RPS-like dynamics have been suggested in many animals and also in plants (Sinervo and Calsbeek, 2006; Sinervo et al., 2007 and its supplement). For example, three classes of male phenotypes have been observed in bluegill sunfish, Lepomis machrochirus, (Gross and Charnov, 1980; Gross, 1991), the salmon Onchorynchus nerka (Gross, 1985), and the guppies Poecilia reticulata (Blows and Brooks, 2003; Blows et al., 2003), and P. parae (Bourne et al., 2003; Lindholm et al., 2004). P. reticulata exhibits FD selection (Olendorf et al., 2006), and trimorphic mate preferences (Blows and Brooks, 2003), and in P. parae changes in morph frequencies and preferences have been observed (Bourne et al., 2003; Lindholm et al., 2004). These observations are in line with those in Z. vivipara, suggesting that FD selection may also be the consequence of FD female mate choice. Moreover, other xiphophorid species also exhibit 3 male morphs (e.g., Xiphophorus nigrensis, Ryan et al., 1992), which suggests that FD preferences might be common in trimorphic fish species in general. Similarly to fish, in birds, at least 2 species have trimorphic mating systems that are congruent with FD selection: the Ruff, Philomacus pugnax, and the Gouldian finch, Erythrura gouldiae (Sinervo, in review). Both the Ruff and Gouldian finch (e.g., Pryke et al., 2007) exhibit female preferences, but whether female preferences are morph FD is not known. Evidence that female preferences may determine the observed rapid cyclic RPS or RPS-like dynamics does not only stem from vertebrates. There exists also evidence from insects. For example in damselflies, trimorphisms of females and rapid evolutionary change of morph frequencies between generations have been observed (Svensson et al., 2005). Moreover, in Ischnura elegans it has been suggested that the morph frequency change may arise from sexual conflict and sexually antagonistic selection (Sinervo and Calsbeek, 2006), which is congruent with our findings from $Z$. vivipara. These lines of evidence thus suggest that sexual selection might be at the origin of the morph frequency cycles observed in insects, isopodes, reptiles, and plants. More specifically, they suggest that FD female mate choice might be an important determinant in different organisms and thus, that sexual selection may be a crucial parameter determining the maintenance of genetic polymorphisms.

\section{AUTHOR CONTRIBUTIONS}

Patrick S. Fitze, Virginia Gonzalez-Jimena, Luis M. San-Jose, and Benoit Heulin captured the lizards and performed the experiments. Patrick S. Fitze and Barry Sinervo analyzed the data and drafted the article, all authors revised and commented the draft.

\section{ACKNOWLEDGMENTS}

We would like to thank two anonymous referees that helped to improve the manuscript. Patrick S. Fitze was supported by funds from Swiss National Science Foundation (PPOOP3_128375), funds from ARAID foundation, and funds from the Spanish Ministry of Education and Science (CGL2005-01187, CGL200801522, and Programa Ramón y Cajal). Virginia Gonzalez-Jimena 
was supported by a $\mathrm{PhD}$ grant from the Spanish Ministry of Education and Science (FPU AP2006-01678), and Luis M. SanJose by a PhD grant (I3P 060501) from the Consejo Superior de Investigaciones Científicas (CSIC) co financed by the European Social Fund. Benoit Heulin was supported by funds from CNRS UMR6553. Barry Sinervo was supported by funds from NSF, the National Geographic Society, the France Berkeley Fund and CNRS. Barry Sinervo would like to thank the University of Toulouse and CNRS Moulis for generously providing facilities, equipment, and a sabbatical position during preparation of this manuscript. The work was performed according to the ABS/ASAB guidelines for ethical treatment of animals an under permits from Navarra, Aragón, and the Parc National des Pyrénées.

\section{REFERENCES}

Ågren, J., and Ericson, L. (1996). Population structure and morph-specific fitness differences in tristylous Lythrum salicaria. Evolution 50, 126-139. doi: $10.2307 / 2410787$

Alonzo, S. H., and Sinervo, B. (2001). Mate choice games, context-dependent good genes, and genetic cycles in the side-blotched lizard, Uta stansburiana. Behav. Ecol. Sociobiol. 49, 176-186. doi: 10.1007/s002650000265

Alonzo, S. H., and Sinervo, B. (2007). The effect of sexually antagonistic selection on adaptive sex ratio allocation. Evol. Ecol. Res. 9, 1097-1117.

Arribas, O. (2009). Morphological variability of the Cantabro-Pyrenean populations of Zootoca vivipara (Jacquin, 1787) with description of a new subspecies. Herpetozoa 21, 123-146.

Bauwens, D., and Verheyen, R. F. (1985). The timing of reproduction in the lizard Lacerta vivipara differences between individual females. J. Herpet. 19, 353-364. doi: $10.2307 / 1564263$

Bleu, J., Le Galliard, J. F., Meylan, S., Massot, M., and Fitze, P. S. (2011). Mating does not influence reproductive investment, in a viviparous lizard. J. Exp. Zool. A Ecol. Genet. Physiol. 315, 458-468. doi: 10.1002/jez.693

Blows, M. W., and Brooks, R. (2003). Measuring nonlinear selection. Am. Nat. 162, 815-820. doi: 10.1086/378905

Blows, M. W., Brooks, R., and Kraft, P. G. (2003). Exploring complex fitness surfaces: multiple ornamentation and polymorphism in male guppies. Evolution 57, 1622-1630. doi: 10.1111/j.0014-3820.2003.tb00369.x

Boudjemadi, K., Lecomte, J., and Clobert, J. (1999). Influence of connectivity on demography and dispersal in two contrasting habitats: an experimental approach. J. Anim. Ecol. 68, 1207-1224. doi: 10.1046/j.1365-2656.1999. 00363. $\mathrm{x}$

Bourne, G. R., Breden, F., and Allen, T. C. (2003). Females prefer carotenoid colored males as mates in the pentamorphic livebearing fish, Poecilia parae. Naturwissenschaften 90, 402-405. doi: 10.1007/s00114-003-0444-1

Cote, J., Le Galliard, J. F., Rossi, J.-M., and Fitze, P. S. (2008). Environmentally induced changes in carotenoid-based coloration of female lizards: a comment on Vercken et al. J. Evol. Biol. 21, 1165-1172. doi: 10.1111/j.14209101.2008.01534.x

Crawley, M. J. (2007). The R Book. West Sussex: John Wiley \& Sons Ltd. doi: 10.1002/9780470515075

Fitze, P. S., Cote, J., and Clobert, J. (2010). Mating order-dependent female mate choice in the polygynandrous common lizard Lacerta vivipara. Oecologia 162, 331-341. doi: 10.1007/s00442-009-1463-1

Fitze, P. S., Cote, J., Martínez-Rica, J. P., and Clobert, J. (2008). Determinants of male fitness: disentangling between intra- and inter-sexual selection. J. Evol. Biol. 21, 246-255. doi: 10.1111/j.1420-9101.2007.01447.x

Fitze, P. S., Cote, J., San-Jose, L. M., Meylan, S., Isaksson, C., Andersson, S., et al. (2009). Carotenoid-based colours reflect the stress response in the common lizard. PLoS ONE 4:e5111. doi: 10.1371/journal.pone.0005111

Fitze, P. S., and Le Galliard, J.-F. (2008). Operational sex ratio, sexual conflict, and the intensity of sexual selection. Ecol. Lett. 11, 432-439. doi: 10.1111/j.14610248.2008.01158.x

Fitze, P. S., and Le Galliard, J.-F. (2011). Inconsistency between different measures of sexual selection. Am. Nat. 178, 256-268. doi: 10.1086/660826

Fitze, P. S., Le Galliard, J.-F., Federici, P., Richard, M., and J., Clobert (2005). Conflict over multiple-partner mating between males and females of the polygynandrous common lizard. Evolution 59, 2451-2459. doi: 10.1111/j.00143820.2005.tb00954.x

Gavaud, J. (1991). Role of cryophase temperature and thermophase duration in thermoperiodic regulation of the testicular cycle in the Lizard Lacerta-vivipara. J. Exp. Zool. 260, 239-246. doi: 10.1002/jez.1402600213

Gonzalez-Jimena, V., and Fitze, P. S. (2012). Blood corticosterone levels and intersexual selection games: best-of-bad-job strategies of male common lizards. Behav. Ecol. Sociobiol. 66, 305-315. doi: 10.1007/s00265-011-1278-z

Gross, M. R. (1985). Disruptive selection for alternative life histories in salmon. Nature 313, 47-48. doi: 10.1038/313047a0

Gross, M. R. (1991). Evolution of alternative reproductive strategies-frequencydependent sexual selection in male blueguill sunfish. Philos. Trans. R. Soc. Lond. Ser. B 332, 59-66.

Gross, M. R., and Charnov, E. L. (1980). Alternative male life histories in bluegill sunfish. Proc. Natl. Acad. Sci. U.S.A. 77, 6937-6940. doi: 10.1073/pnas.77.11.6937

Heulin, B., Osenegg, K., and Lebouvier, M. (1991). Timing of embryonic development and birth dates in oviparous and viviparous strains of Lacerta vivipara: testing the predictions of an evolutionary hypothesis. Acta Oecol. 12, 517-528.

Huyghe, K., San-Jose, L. M., Peñalver Alcázar, M., and Fitze, P. S. (2013). An ecomorphological analysis of the determinants of mating success. Biol. J. Linn. Soc. 110, 658-664. doi: 10.1111/bij.12140

Kerr, B., Riley, M. A., Feldman, M. W., and Bohannan, B. J. M. (2002). Local dispersal promotes biodiversity in a real-life game of rock-paper-scissors. Nature 418, 171-174. doi: 10.1038/nature00823

Le Galliard, J.-F., Cote, J., and Fitze, P. S. (2008). Lifetime and intergenerational fitness consequences of harmful male interactions for female lizards. Ecology 89, 56-64. doi: 10.1890/06-2076.1

Le Galliard, J.-F., Fitze, P. S., Ferrière, R., and Clobert, J. (2005). Sex ratio bias, male aggression, and population collapse in lizards. Proc. Natl. Acad. Sci. U.S.A. 102, 18231-18236. doi: 10.1073/pnas.0505172102

Lindholm, A. K., Brooks, R., and Breden, F. (2004). Extreme polymorphism in a Y-linked sexually selected trait. Heredity 92, 156-162. doi: 10.1038/sj.hdy.6800386

Marquis, O., Massot, M., and Le Galliard, J. F. (2008). Intergenerational effects of climate generate cohort variation in lizard reproductive performance. Ecology 89, 2575-2583. doi: 10.1890/07-1211.1

Maynard Smith, J. (1982). Evolution and the Theory of Games. Cambridge: Cambridge University Press. doi: 10.1017/CBO9780511806292

Milá, B., Surget-Groba, Y., Heulin, B., Gosá, A., and Fitze, P. S. (2013). Multilocus phylogeography of the common lizard Zootoca vivipara at the Ibero-Pyrenean suture zone reveals lowland barriers and high-elevation introgression. BMC Evol. Biol. 13:192. doi: 10.1186/1471-2148-13-192

Nowak, M. A. (2006). Evolutionary Dynamics: Exploring the Equations of Life. Cambridge, MA: Harvard University Press.

Olendorf, R., Rodd, F. H., Punzalan, D., Houde, A. E., Hurt, C., Reznick, D. N., et al. (2006). Frequency-dependent survival in natural guppy populations. Nature 441, 633-636. doi: 10.1038/nature04646

Pryke, S. R., Astheimer, L. B., Buttemer, W. A., and Griffith, S. C. (2007). Frequencydependent physiological trade-offs between competing colour morphs. Biol. Lett. 3, 494-497. doi: 10.1098/rsbl.2007.0213

Ryan, M. J., Pease, C. M., and Morris, M. R. (1992). A genetic-polymophism in the swordtail Xiphoporus nigrensis-testing the prediction of equal fitnesses. Am. Nat. 139, 21-31. doi: 10.1086/285311

San-Jose, L. M., and Fitze, P. S. (2013). Corticosterone regulates multile colour traits in Lacerta [Zootoca] vivipara males. J. Evol. Biol. 26, 2681-2690. doi: 10.1111 /jeb. 12265

San-Jose, L. M., Gonzalez-Jimena, V., and Fitze, P. S. (2008). Frequency and phenotypic differences of melanistic and normally colored common Lizards, Lacerta (Zootoca) vivipara of the Southern Pyrenees (Spain). Herpet. Rev. 39, 422-425.

San-Jose, L. M., Granado-Lorencio, F., and Fitze, P. S. (2012a). Vitamin E, Vitamin A, and carotenoids in male common lizard tissues. Herpetologica 68, 88-99. doi: 10.1655/HERPETOLOGICA-D-11-00029.1

San-Jose, L. M., Granado-Lorencio, F., and Fitze, P. S. (2012b). Dietary lipids reduce the expression of carotenoid-based coloration in Lacerta vivipara. Funct. Ecol. 26, 646-656. doi: 10.1111/j.1365-2435.2012.01970.x

San-Jose, L. M., Granado-Lorencio, F., Sinervo, B., and Fitze, P. S. (2013). Iridophores and not carotenoids account for chromatic variation of 
carotenoid-based coloration in common lizards (Lacerta vivipara). Am. Nat. 181, 396-409. doi: 10.1086/669159

San-Jose, L. M., Peñalver-Alcázar, M., Milá, B., Gonzalez-Jimena, V., and Fitze, P. S. (2014). Cumulative frequency-dependent selective episodes allow for rapid morph cycles and rock-paper-scissors dynamics in species with overlapping generations. Proc. R. Soc. B 281:20140976. doi: 10.1098/rspb.2014.0976

Shuster, S., and Wade. M. (1991). Equal mating success among male reproductive strategies in a marine isopod. Nature 350, 608-610. doi: 10.1038/350608a0

Sinervo, B., Bleay, C., and Adamopoulou, C. (2001). Social causes of correlational selection and the resolution of a heritable throat color polymorphism in a lizard. Evolution 55, 2040-2052. doi: 10.1111/j.0014-3820.2001.tb01320.x

Sinervo, B., and Calsbeek, R. (2006). The developmental, physiological, neural, and genetical causes and consequences of frequency-dependent selection in the wild. Annu. Rev. Ecol. Evol. Syst. 37, 581-610. doi: 10.1146/annurev.ecolsys.37.091305. 110128

Sinervo, B., and Clobert, J. (2003). Morphs, dispersal behavior, genetic similarity, and the evolution of cooperation. Science 300, 1949-1951. doi: 10.1126/science. 1083109

Sinervo, B., Heulin, B., Surget-Groba, Y., Clobert, J., Miles, D. B., Corl, A., et al. (2007). Models of density-dependent genic selection and a new rock-paperscissors social system. Am. Nat. 170, 663-680. doi: 10.1086/522092

Sinervo, B., and Lively, C. M. (1996). The rock-paper-scissors game and the evolution of alternative male strategies. Nature 380, 240-243. doi: 10.1038/ 380240a0

Svensson, E. I., Abbott, J., and Hardling, R. (2005). Female polymorphism, frequency dependence, and rapid evolutionary dynamics in natural populations. Am. Nat. 165, 567-576. doi: 10.1086/429278

Vercken, E., Massot, M., Sinervo, B., and Clobert, J. (2007). Colour variation and alternative reproductive strategies in females of the common lizard
Lacerta vivipara. J. Evol. Biol. 20, 221-232. doi: 10.1111/j.1420-9101.2006. 01208.x

Vercken, M., Clobert, J., and Sinervo, B. (2010). Frequency-dependent reproductive success in female common lizards: a real-life hawk-dove-bully game? Oecologia 162, 49-58. doi: 10.1007/s00442-009-1442-6

Zhang, R., Clark, A. G., and Fiumera, A. C. (2013). Natural genetic variation in male reproductive genes contributes to nontransitivity of sperm competitive abilitiy in Drosophila melanogaster. Mol. Ecol. 22, 1400-1415. doi: $10.1111 / \mathrm{mec} .12113$

Conflict of Interest Statement: The authors declare that the research was conducted in the absence of any commercial or financial relationships that could be construed as a potential conflict of interest.

Received: 19 May 2014; accepted: 14 November 2014; published online: 03 December 2014.

Citation: Fitze PS, Gonzalez-Jimena V, San-Jose LM, Heulin B and Sinervo B (2014) Frequency-dependent sexual selection with respect to progeny survival is consistent with predictions from rock-paper-scissors dynamics in the European common lizard. Front. Ecol. Evol. 2:77. doi: 10.3389/fevo.2014.00077

This article was submitted to Behavioral and Evolutionary Ecology, a section of the journal Frontiers in Ecology and Evolution.

Copyright (C) 2014 Fitze, Gonzalez-Jimena, San-Jose, Heulin and Sinervo. This is an open-access article distributed under the terms of the Creative Commons Attribution License (CC BY). The use, distribution or reproduction in other forums is permitted, provided the original author(s) or licensor are credited and that the original publication in this journal is cited, in accordance with accepted academic practice. No use, distribution or reproduction is permitted which does not comply with these terms. 